\title{
NEW POSSIBILITIES FOR SUPERCONDUCTING CAVITY TESTING AT CORNELL UNIVERSITY*
}

\author{
M. Liepe ${ }^{\dagger}$, P. Barnes, I. Bazarov, S. Belomestnykh, R.L. Geng, \\ H. Padamsee, J. Sears, Cornell University, Ithaca, NY, 14853, USA \\ J. Knobloch, BESSY, D-12489 Berlin, Germany
}

\section{Abstract}

Cornell is testing superconducting cavities for many different purposes: system development for CESR, supporting technology transfer of CESR SRF systems to storage ring light sources around the world, collaboration with the world-wide TESLA project, collaboration with Muon Collider/Neutrino Factory projects, developing an Energy Recovery Linac (ERL) based synchrotron light source in collaboration with TJNAF, and basic cavity R\&D in the areas of high Q, high field Q-slope and field emission.

For this Cornell has upgraded its preparation and test facilities and now has the capabilities to test s.c cavities with frequencies between $200 \mathrm{MHz}$ and $3 \mathrm{GHz}$. Three radiationshielded test pits have been built. The largest pit has a size of $2.4 \mathrm{~m}$ diameter by 4.4 meter deep. In addition to the existing RF test system at $500 \mathrm{MHz}, 1.3 \mathrm{GHz}$ and $1.5 \mathrm{GHz}$, a $200 \mathrm{MHz}$ low power $(2 \mathrm{~kW}) \mathrm{RF}$ test system has been completed [1]. The high-power $1.3 \mathrm{GHz}$ test system as well as the cavity preparation facility are presently being upgraded to incorporate TESLA 9-cell cavities. A new $1000 \mathrm{sq} \mathrm{ft}$ clean room is in operation for improved cavity preparation.

\section{NEW FACILITIES}

In a two year effort Cornell University has upgraded its cavity preparation and test facilities. A new clean room and cavity test pits give the unique capability to test superconducting RF cavities with frequencies as low as $200 \mathrm{MHz}$ or a length of more than $2 \mathrm{~m}$.

\section{CAVITY TEST PITS}

In a new cavity test area three test pits of different sizes have been excavated.

- Small test pit: $1 \mathrm{~m}$ diameter by $2.9 \mathrm{~m}$ deep for 1.5 $\mathrm{GHz}$ and higher frequency cavity tests.

- Medium test pit: $1.6 \mathrm{~m}$ diameter by $3 \mathrm{~m}$ deep for 500 $\mathrm{MHz}$ and $1.3 \mathrm{GHz}$ cavity tests. A waveguide can be connected to the $1.3 \mathrm{GHz}$ insert for pulsed high power tests.

- Large test pit: $2.4 \mathrm{~m}$ diameter by $4.4 \mathrm{~m}$ deep for 200 $\mathrm{MHz}$ and $1.3 \mathrm{GHz}$ multicell cavity tests. Also this pit can be connected to the $1.3 \mathrm{GHz}$ klystron for pulsed high power tests.

\footnotetext{
${ }^{*}$ Work is supported by the National Science Foundation.

†mul2@ cornell.edu
}

The small and large size pits are shown in Figure 1. A radiation shielding block with 90 tons of high density concrete can be moved over a selected pit during cavity test while the other two pits are accessible for cavity installation or removal. Up to three cavity tests within one week have been done with this new test facility.

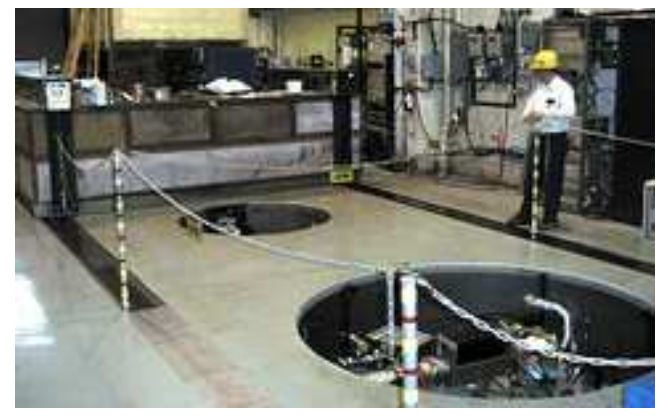

Figure 1: Test pits for various size cavities. Shown is the small and the large pit. Not shown is the medium size pit.

\section{CLEAN ROOM}

For improved cavity preparation a new clean room with a total size of about $1000 \mathrm{sq} \mathrm{ft}$ has been installed; see Figure 2. With $262 \mathrm{sq} \mathrm{ft}$ of class 1,000 area and $704 \mathrm{sq} \mathrm{ft}$ of class 100 area this clean room allows to prepare cavities for $\mathrm{cw}$ performance tests and to assemble whole cryostats with a length up to about $5 \mathrm{~m}$. A high temperature high vacuum furnace for cavity post-purification and a highpressure rinsing system for cavity cleaning are placed inside the clean room.

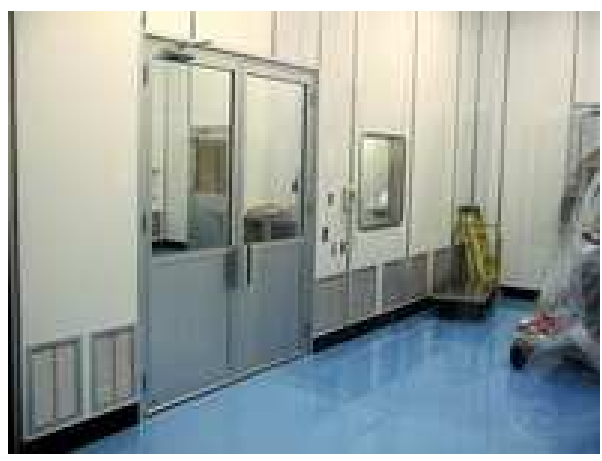

Figure 2: New 1000 sq ft clean room. 


\section{HPR SYSTEM}

A new high-pressure (up to 900 psi) water rinsing system has been built and installed in a class 100 area of the new clean room; see Figure 3. While the cavity is moving up or down, a nozzle head rotates to clean the inner cavity surface. Ultra-clean water is filtered once more directly before the nozzle head by a $0.1 \mu \mathrm{m}$ teflon particle filter. The rinsing system has been designed to incorporate cavities from $1.5 \mathrm{GHz}$ up to $500 \mathrm{MHz}$. With a travel range of about $120 \mathrm{~cm}$, multicell cavities like a TESLA 9-cell cavity can be rinsed in one step.

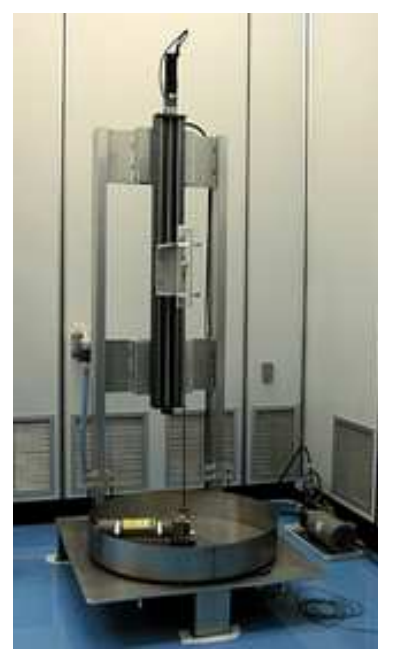

Figure 3: New high-pressure water rinsing system.

\section{CAVITY TEST SYSTEMS}

\section{$200 \mathrm{MHz}$}

The proposed neutrino factory and muon collider ask for RF cavities operating at a frequency near $200 \mathrm{MHz}$ for rapid acceleration of muons [2]. One scenario is to use superconducting RF cavities [3]. The desired accelerating gradient is $17 \mathrm{MV} / \mathrm{m}$ at an unloaded quality factor of $6 \cdot 10^{9}$. Since there was no superconducting RF experience at 200 $\mathrm{MHz}$, an R\&D program was started. Two $200 \mathrm{MHz}$ single cell elliptical $\mathrm{Nb}$ sputtered $\mathrm{Cu}$ cavities have been fabricated by CERN at tested at Cornell University. Figure 6 shows a $200 \mathrm{MHz}$ cavity mounted on the test insert for a cw cavity performance test in the large test pit. A $2 \mathrm{~kW} \mathrm{cw} \mathrm{RF} \mathrm{am-}$ plifier is available to power the cavity during test. Several tests have be done so far; refer to [1] for details.

\section{$500 \mathrm{MHz}$}

The $500 \mathrm{MHz}$ cw cavity test insert with a cavity mounted is shown in Figure 6. A $500 \mathrm{~W}$ cw amplifier is used to drive the cavity during a performance test. In the past years this insert was used for cavity qualification tests prior to the installation of a cavity in a cryostat. In the future we plan to test $\mathrm{Nb}$ sputtered $500 \mathrm{MHz}$ cavities to continue the work

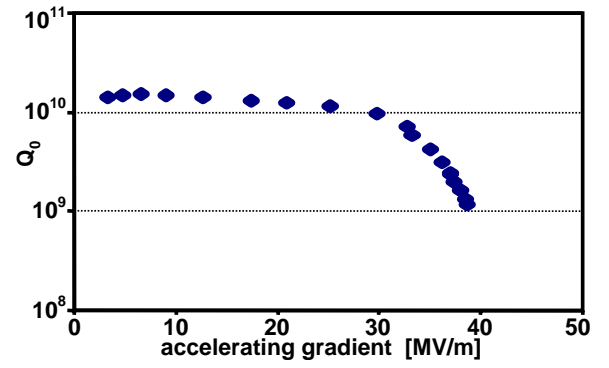

Figure 4: $\mathrm{Cw}$ performance of a $1.3 \mathrm{GHz}$ electropolished single-cell cavity (EP done at CERN).

on sputtered SRF cavities.

For a full system test a $500 \mathrm{MHz}$ horizontal cryostat test facility is in operation with a $600 \mathrm{~kW} \mathrm{cw}$ klystron to power the cavity. All CESR cryostats are tested to verify their performance before installing them in the CESR ring.

\section{$1300 \mathrm{MHz}$}

About 10 years ago the work on s.c. $1.3 \mathrm{GHz}$ cavities for the proposed TESLA linear collider was started at Cornell. A cavity test insert for low power cw test and high power pulsed test was built, see Figure 6. Via a waveguide the cavity under test can be powered from a cw 200 $\mathrm{W}$ amplifier or a $2 \mathrm{MW}$ pulsed klystron. High peak power processing allowed to reach record high fields in the early days of these studies. Today's improved cavity preparation allows to reach high fields during a performance test without any X-rays, see for example Figure 4.

Since the "old" $1.3 \mathrm{GHz}$ insert is limited to 1 to 5 cell cavities a new $1.3 \mathrm{GHz}$ cavity insert with waveguide coupler is under construction; see Figure 5. This new setup will allow to test cavities with a length of up to $2 \mathrm{~m}$, e.g. TESLA 9-cell cavities.

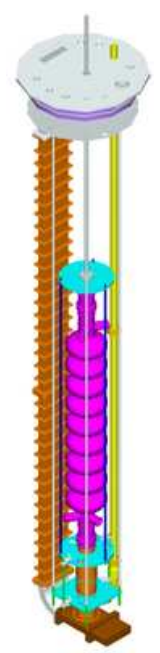

Figure 5: Sketch of the $1.3 \mathrm{GHz}$ cavity insert under construction. 

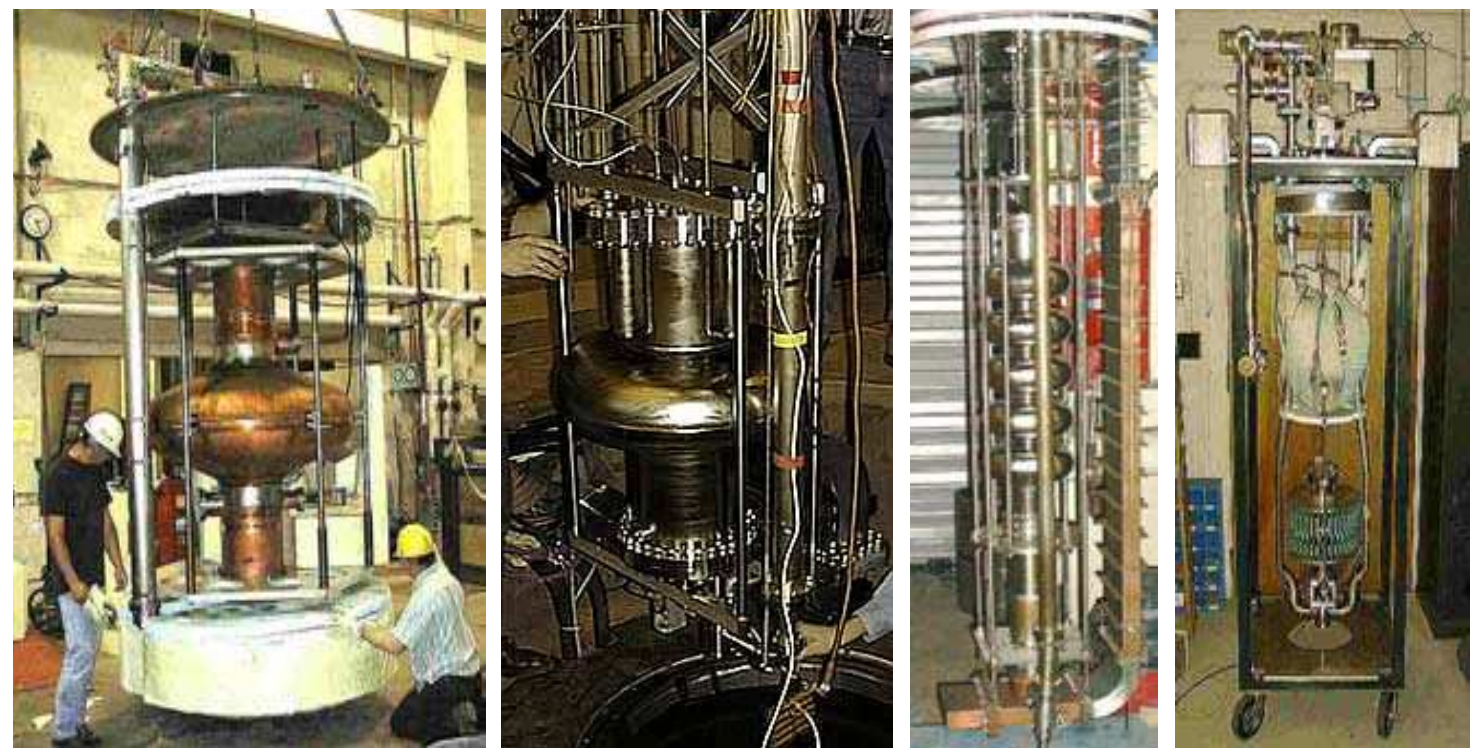

Figure 6: Cavity test inserts for various frequencies. From left to right: $200 \mathrm{MHz}$ system, $500 \mathrm{MHz}$ system, $1300 \mathrm{MHz}$ system and $1500 \mathrm{MHz}$ system.

\section{$1500 \mathrm{MHz}$}

The $1500 \mathrm{MHz}$ single-cell cw test system (see Figure 6) is used frequently for basic cavity R\&D. With its temperature mapping system [4] it provides a powerful tool to study the high field behavior of SRF cavities. Recent studies focused on the high-field Q-drop and electropolished cavities [5].

\section{FUTURE PLANS}

Cornell will continue its work in basic SRF cavity R\&D as well as in RF system development. While in the last years the primary effort of the SRF program was the development, construction, installation and operation of the 500 MHz CESR SRF system, in the upcoming years we will broaden our high gradient, high Q cavity studies for future light sources and the proposed TESLA linear collider. Cornell University, in collaboration with TJNAF, has proposed the development and construction of an Energy Recovery Linac (ERL) based synchrotron light source [6]. Such a machine offers superior $\mathrm{x}$-ray beams compared to storage ring sources due to a significantly better beam quality. In order to develop the required technology and to demonstrate the feasibility of a high current, low emittance ERL we are proposing the construction of an $100 \mathrm{MeV}, 100 \mathrm{~mA}$ ERL prototype at Cornell [7]. Central parts of this machine are the superconducting injector linac with 2-cell cavities and the main linac with energy recovery. Many challenges like the $\mathrm{cw}$ cavity operation at high gradients, HOM damping, emittance preservation, high $\mathrm{cw}$ power input couplers and RF field control needs attention to develop the SRF system for the ERL prototype. With the new SRF facilities we have the infrastructure to address these challenges, and work is in progress; refer to $[8,9,10,11,12,13,14,15]$.

\section{REFERENCES}

[1] R.L. Geng et al., this conference, paper TPAB049.

[2] Feasibility Study-II of a Muon-Based Neutrino Source, ed., S. Ozaki, R. Palmer, M. Zisman, and J. Gallardo, BNL52623 (2001).

[3] H. Padamsee, SRF for muon colliders, Proceedings of the 9th workshop on RF superconductivity, 587 (1999).

[4] J. Knobloch, Ph.D. thesis, Cornell University, CLNS thesis 97-3 (1997).

[5] R.L. Geng et al., this conference, paper TPAB050.

[6] Study for a proposed Phase I ERL Synchrotron Light Source at Cornell University, ed. by S. Gruner and M. Tigner, CHESS Tech. Memo 01-003, JLAB-ACT-01-04 (July 2001).

[7] C. Sinclair et al., this conference, paper TOAC005.

[8] H. Padamsee at al., this conference, paper TPAB052.

[9] V. Veshcherevich, this conference, paper TPAB009.

[10] V. Veshcherevich, this conference, paper TPAB008.

[11] V. Shemelin et al., this conference, paper WPAB012.

[12] M. Liepe and S. Belomestnykh, this conference, paper TPAB056.

[13] M. Liepe et al., this conference, paper FPAB027.

[14] M. Liepe et al., this conference, paper TPAB053.

[15] Z. Greenwald, this conference, paper WPAB011. 